\title{
Spin-Orbit Coupling and Magnetic Field Effects in Photoredox Reactions of Ruthenlum(II) Complexes
}

\author{
Ulrich E. Steiner, ${ }^{*}$ Hans-Joachim Wolff, Thomas Ulrich, ${ }^{\dagger}$ \\ Fakultät für Chemie, Universität Konstanz, D-7750 Konstanz, FRG \\ and Takeshi Ohno \\ College of General Education, Osaka University, Toyonaka, Osaka 560, Japan
}

\begin{abstract}
Spin-orbit coupling (SOC) and magnetic field effects (MFEs) on the efficiency $\eta_{\text {net }}$ of net electron transfer in the reductive and oxidative quenching of excited $\mathrm{Ru}^{\mathrm{II}}$ trisbipyridyl complexes have been investigated by nanosecond laser flash spectroscopy and by a special continuous photolysis technique. The reductive process was studied with tris $\left[4,4^{\prime}\right.$-bis(ethoxycarbonyl)$2,2^{\prime}$-bipyridine] ruthenium( $2+$ ) quenched by anilines $\mathrm{X}-\mathrm{An}(\mathrm{X}=\mathrm{H}, 4-\mathrm{Cl}, 4-\mathrm{Br}, 2-\mathrm{I}, 4-\mathrm{I})$. Increasing SOC of the substituent $\mathrm{X}$ leads to a decrease of relative $\eta_{\text {net }}$ values $(1.0,0.79,0.45,0.22,0.12)$. With $X=4-\mathrm{I} \eta_{\text {net }}$ is decreased by $12.5 \pm 2.5 \%$ in a magnetic field of $1 \mathrm{~T}$. These effects are interpreted as SOC effects of the $\mathrm{X}$ center on the spin-forbidden back electron transfer in triplet radical pairs. The oxidative process was studied with $\left[\mathrm{Ru}^{\mathrm{II}}\left(2,2^{\prime} \text {-bipyridine }\right)_{3}\right]^{2+}$ and methylviologen $\left(\mathrm{MV}^{2+}\right)$ as a quencher. Here a MFE of $-10 \%$ at $1 \mathrm{~T}$ was observed on the yield of radicals detected on the nanosecond time scale. A detailed MF dependence between 0 and $1 \mathrm{~T}$ of the yield of $\mathrm{MV}^{\circ+}$ radicals was measured by continuous photolysis using EDTA as a sacrificial electron donor to reduce $\mathrm{Ru}^{\mathrm{III}}$. The MFE shows a gradual onset followed by a linear increase above 50-100 mT. The onset field decreases and the (negative) slope of the MFE increases as the solvent viscosity is increased in water/ethylene glycol mixtures. On the basis of measurements of lifetime and radical yield at various quencher concentrations, it is shown that the magnetic field mainly affects $\eta_{\text {net }}$ and not the rate of quenching $k_{\mathrm{q}}$, as recently asserted by other authors. The MFE is attributed to SOC effects in the $\mathrm{Ru}^{\mathrm{III}}$ complex constituent of the primary radical pair. Novel theoretical aspects arising in connection with the magnetokinetic behavior of radical pairs involving a strongly spin-orbit mixed Kramers doublet are outlined.
\end{abstract}

\section{Introduction}

During the past two decades it has been convincingly documented that magnetic field effects in chemical reactions can provide a valuable source of information concerning the intriguing interplay between spin motion, molecular diffusional dynamics, and chemical reactivity. ${ }^{3}$ This applies in particular to such reactions where radical pairs (RPs) are involved as reactive intermediates. Magnetic field effects according to the so-called radical-pair mechanism have been studied with a great many of chemical systems in various environments and include also the study of primary events in photosynthetic reaction centers. ${ }^{2,3}$ In most cases where RPs are responsible for magnetokinetic effects a magnetic field partially suppresses coherent transitions brought about by isotropic hyperfine coupling between RP spin states of singlet and triplet multiplicity. In this way the radical pair's spin

${ }^{\dagger}$ Present address: Ilford AG, WFM 160.030, CH-1701 Fribourg, Switzerland. memory concerning the multiplicity of its precursor state is prolonged and, depending on whether this was singlet or triplet, a higher or lower probability of geminate recombination than in zero field is observed. Magnetic field dependent spin relaxation processes may also have an effect on geminate RP recombination kinetics. However, since paramagnetic relaxation is generally much slower than the coherent processes based on isotropic hyperfine coupling, their kinetic manifestation requires longer periods between geminate reencounters. Such conditions are met, for example, by RPs solubilized in micelles ${ }^{4}$ or in microemulsions. ${ }^{5,6}$

(1) For recent reviews, see: (a) Salikhov, K. M.; Molin, Yu. N.: Sagdeev, R. Z.; Buchachenko, A. L. Spin Polarization and Magnetic Effects in Radica Reactions; Elsevier: Amsterdam 1984. (b) Gould, I. R.; Turro, N. J.; Zimmt, M. B. Adv. Phys. Org. Chem. 1984, 20, 1. (c) Steiner, U. E.; Ulrich, T. Chem. Rev. 1989, 89, 51 .

(2) Hoff, A. J. Photochem. Photobiol. 1986, 43, 727.

(3) Boxer, S. G.; Chidsey, C. E. D.; Roelofs, M. G. Annu. Rev. Phys. Chem. 1983, 34, 389 . 
An increase of spin-orbit coupling (SOC) in systems showing magnetic field effects according to the RP mechanism may cause two effects. On the one hand, due to a difference of the $g$ factors that arises if SOC is more efficient in one radical than in the other, there is an increased singlet-triplet mixing in a magnetic field due to the coupling matrix element $\mu_{\mathrm{B}} \Delta g \mathbf{B}_{0}\left\langle\mathrm{~S}\left|\hat{s}_{1}-\hat{s}_{2}\right| \mathrm{T}_{0}\right\rangle$, such that at high fields the kinetic effect caused by suppression of the hyperfine coupling induced $\mathrm{S} \rightarrow \mathrm{T}_{ \pm}$mixing may be compensated by the $\Delta g$-induced $S \rightarrow T_{0}$ mixing. On the other hand, SOC often causes g-tensor anisotropy and thus establishes a coupling between electron spin orientation and molecular orientation which provides a mechanism of spin relaxation. Such a mechanism must be particularly efficient with small linear inorganic radicals like $\mathrm{OH}^{\cdot 7}$ or $\mathrm{N}_{3}{ }^{\cdot 8}$ Increasing rates of spin relaxation will tend to diminish any magnetokinetic effect. Examples of such quenching of magnetic field effects as a consequence of heavy-atom substitution of RP constituents have been reported for micellar systems. ${ }^{6}$

Still another effect may arise in cases of enhanced SOC if this mechanism induces processes that compete with chemical reactions or if it is directly responsible for a spin-forbidden chemical reaction. Such processes can be expected in molecular triplet states, exciplexes, biradicals, or contact RPs. Their rate constants are usually assumed to be proportional to the square of matrix elements of the type $\left\langle\mathrm{S}\left|\hat{H}_{\mathrm{Soc}}\right| \mathrm{T}\left(\Gamma_{\mathrm{a}}\right)\right\rangle$, where $\Gamma_{\mathrm{a}}$ denotes the symmetry species of a particular triplet spin component. If the matrix elements are largely different among the symmetry species $\Gamma_{i}$ spanning the triplet spin space, a spin-sublevel-selective reaction or decay rate will ensue. Since at a general orientation of the triplet with regard to an external magnetic field the Zeeman interaction $\mu_{\mathrm{B}} g \mathbf{B}_{0}\left\langle\mathbf{T}\left(\Gamma_{\mathrm{a}}\right)\left|\hat{s}_{1}+\hat{s}_{2}\right| \mathrm{T}\left(\Gamma_{i}\right)\right\rangle$ will couple the various triplet components of different molecular symmetry, the sublevel selectivity of reaction or decay will be lost as the magnetic field increases. The effect of this so-called triplet mechanism on chemical yields has been analyzed in some detail, ${ }^{9-11}$

With the various possibilities of interplay between SOC and magnetic field dependence of chemical reaction kinetics in mind, one might wonder if and of what type one might find magnetic field effects in reactions involving transition-metal complexes, where the amount of SOC is often very pronounced due to the high nuclear charge and the partially unquenched orbital angular momentum of the d-shell electrons in a ligand field of high symmetry. In fact, there have so far been several reports in the literature dealing with magnetic field dependent thermal or enzymatic reactions where transition metals are involved. These include hydrogen peroxide decomposition by $\mathrm{Fe}^{3+}$ ions, ${ }^{12}$ reduction of aryl diazonium salts by $\mathrm{Fe}^{2+}$ ions, ${ }^{13}$ and thermal oxidation of 2,6-di-tert-butylphenol with molecular oxygen catalyzed by certain Co and Mn complexes. ${ }^{14}$ Furthermore, some enzymatic systems involving the heme enzymes catalase and cytochrome P-450 were reported to show magnetic field dependence. ${ }^{12}$ Although no detailed theoretical analysis has been provided for any of these effects, it is assumed that mechanisms of the radical-pair type are responsible for them.

Other magnetic field effects in transition-metal photochemistry have been reported by Ferraudi and co-workers, ${ }^{15,16}$ who found

(4) Hayashi, H.; Nagakura, S. Bull. Chem. Soc. Jpn. 1984, 57, 322

(5) Ulrich, T.; Steiner, U. E. Chem. Phys. Lett. 1984, $112,365$.

(6) Ulrich, T.; Steiner, U. E.; Schlenker, W. Tetrahedron 1986, 42, 6131

(7) Brocklehurst, B. Int. Rev. Phys. Chem. 1985, 4, 279 547 .

(9) Ulrich, T.; Steiner, U. E.; Föll, R. E. J. Phys. Chem. 1983, 87, 1873

(10) Steiner, U. E. Ber. Bunsen-Ges. Phys. Chem. 1981, 85, 228.

(11) Serebrennikov, Yu. A.; Minaev, B. F. Chem. Phys. 1987, 114, 359

(12) Molin, Yu. N.; Sagdeev, R. Z.; Leshina, T. V.; Podoplelov, A. V.:

Dushkin, A. V.; Grishin, Yu. A.; Weiner, L. M. Magnetic Resonance and Related Phenomena; Kundla, E., Lippmaa, E., Saluvere, T., Eds.; Springer: Berlin, 1979; p 49.

(13) Samarskaya, T. G.; Skrunts, L. K.; Kiprianova, L. A.; Levit, I. P.;

Gragerov, 1. P. Dokl. Phys. Chem. 1985, 283, 697.

(14) Perito, P.; Corden, B. B. J. Am. Chem. Soc. 1987, 109, 4418

(15) Ferraudi, G.; Pacheco, M. Chem. Phys. Lett. 1984, 112, 187. 64.

(16) Ferraudi, G.; Argüello, G. A.; Frink, M. E. J. Phys. Chem. 1987, 9 I, marked effects on the quantum yields of photoaquation of [Rh$\left.\left(\mathrm{NH}_{3}\right)_{5} \mathrm{X}\right](\mathrm{X}=\mathrm{Cl}, \mathrm{Br})$ and of $\mathrm{K}_{2}\left[\mathrm{Co}(\mathrm{CN})_{6}\right]$ in magnetic fields up to $2.4 \mathrm{~T}$ applied in a pulsed fashion. As a mechanistic explanation of the magnetic field effect in the latter case, a fieldinduced change in the state correlation pattern between various triplet terms of the excited hexacoordinated precursor and the pentacoordinated singlet ground state of the primary product was discussed.

An appreciable magnetic field effect on the rate of photochemical $\mathrm{H}_{2}$ evolution has been observed by Kiwi ${ }^{17}$ when using the $\mathrm{Ru}^{\mathrm{II}}$ trisbipyridyl complex [Ru(bpy) $]_{3}{ }^{2+}$ as a photosensitizer in combination with a modified semiconductor catalyst and EDTA as a sacrificial electron donor. The magnetic field effect also occurred when methylviologen $\left(\mathrm{MV}^{2+}\right)$ was added as an electron relay. A magnetic field effect was, however, not found with direct UV irradiation of the semiconductor suspension in the absence of the sensitizer system, nor on the yield of $\mathrm{MV}^{\bullet+}$ radicals in the homogeneous $\left[\mathrm{Ru}(\mathrm{bpy})_{3}\right]^{2+} / \mathrm{MV}^{2+} /$ EDTA system. Therefore, it was concluded that the magnetic field sensitive step is related to radical recombination on the semiconductor surface. In the course of our studies concerning the role of spin-orbit coupling on determining the efficiency of free-radical production in photoelectron-transfer reactions, $8,9,18-20$ we have now investigated the influence of external magnetic fields on corresponding reactions involving complexes of the $\left[\mathrm{Ru}(\mathrm{bpy})_{3}\right]^{2+}$ type. Photooxidation of the complex was studied with the $\left[\mathrm{Ru}(\mathrm{bpy})_{3}\right]^{2+} / \mathrm{MV}^{2+}$ system. Photoreduction reactions of the complex were investigated with $\left[\mathrm{Ru}(\mathrm{dce})_{3}\right]^{2+}\left(\mathrm{dce}=4,4^{\prime}\right.$-bis(ethoxycarbonyl)-2,2'-bipyridine) using aniline and several halogen anilines as electron donors.

During the preparation of our paper an article was published by Ferraudi and Argüello ${ }^{21}$ reporting the magnetic field dependence of the rate constant $\left(k_{0}\right)$ of decay of ${ }^{3}\left[\mathrm{Ru}(\mathrm{bpy})_{3}\right]^{2+}$ in aqueous solutions and the rate constants of its quenching $\left(k_{q}\right)$ by $\mathrm{MV}^{2+}$ and $\mathrm{Co}^{\mathrm{III}}$ complexes. Pulsed fields were applied between 0.8 and $5 \mathrm{~T}$. Whereas the rate konstant $k_{0}$ increased linearly by $13 \%$ up to a field of $4 \mathrm{~T}, k_{\mathrm{q}}$ was reported to increase for the $\mathrm{Co}^{\mathrm{III}}$ quenchers but to decrease for $\mathrm{MV}^{2+}$ as quencher $(-32 \%$ at $3-5$ T). These quenching rate constants were evaluated from measurements of the relative quantum yields of charge-transfer products. Whereas in the work of Ferraudi and Argüello no observation was made between 0 and $0.8 \mathrm{~T}$, our experiments with the $\mathrm{Ru}^{\mathrm{Il}} / \mathrm{MV}^{2+}$ system yield a detailed picture of the magnetic field effect at low fields between 0 and $1 \mathrm{~T}$. Our methods of investigation were also different. We applied a continuous irradiation technique and nanosecond time-resolved laser flash spectroscopy. Our results confirm those of Ferraudi and Argüello as far as the magnetic field effect on the yield of charge-transfer products is concerned. We give, however, a more detailed kinetic analysis and show that the magnetic field effect is not connected with $k_{\mathrm{q}}$ as assumed by Ferraudi and Argüello but with the efficiency of fast back electron transfer (BET) in the primary charge-transfer product. Furthermore the results reported and discussed in this paper cast some light on the problem to what extent the total electron spin of a "radical pair" is defined if a transition-metal complex is involved and how the concept of spin motion may be applied to account for the magnetic field dependence of fast BET efficiency in such systems.

\section{Experimental Section}

2.1. Materials. $\mathrm{Ru}^{\mathrm{II}}\left(2,2^{\prime} \text {-bipyridine }\right)_{3} \mathrm{Cl}_{2} \cdot 6 \mathrm{H}_{2} \mathrm{O}\left(\left[\mathrm{Ru}(\text { bpy })_{3}\right]^{2+}\right)$ and $\mathrm{Ru}^{\mathrm{II}}\left(4,4^{\prime} \text {-bis(ethoxycarbonyl)-2,2'-bipyridine }\right)_{3}\left(\mathrm{ClO}_{4}\right)$ $\left(\left[\mathrm{Ru}(\mathrm{dce})_{3}\right]^{2+}\right)$ were synthesized as reported in the literature. ${ }^{22-24}$

(17) Kiwi, J. J. Phys. Chem. 1983, 87, 2274.

(18) Steiner, U. E.; Winter, G. Chem. Phys. Lett. 1978, 55, 364. 1203 .

(19) Winter, G.; Steiner, U. E. Ber. Bunsen-Ges, Phys. Chem. 1980, 84,

(20) (a) Ohno, T.; Kato, S.; Yamada, A.; Tanno, T. J. Phys. Chem. 1983, 87, 775. (b) Ohno, T.; Kato, S. J. Phys. Chem. 1984, 88, 1670. (c) Ohno, T.; Kato, S. Bull. Chem. Soc. Jpn. 1984, 57, is28. (d) Ohno, T. Coord. Chem. Rev. 1985, 64, 3I1. (e) Ohno, T.; Yoshimura, A.; Mataga, N. J. Phys. Chem. 1986, 90, 3295. (f) Ohno, T.; Yoshimura, A.; Shioyama, H.; Mataga, N. J. Phys. Chem. 1987, 91, 4365.

(21) Ferraudi, G.; Argüello, G. A. J. Phys. Chem. 1988, 92, 1846. 


\section{SCHEME I}

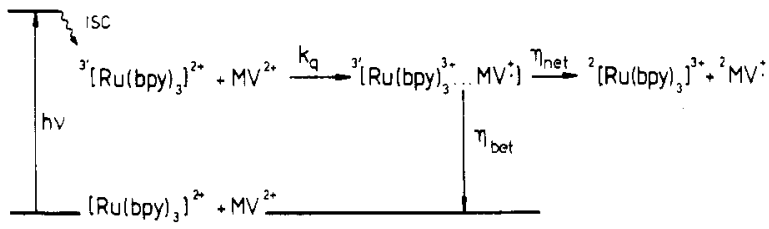

Aniline (Merck, p.a.) was distilled in vacuo, 4-bromoaniline (Merck, $>99 \%$ ), 2-iodoaniline (Merck-Schuchardt, $\geq 98 \%$ ) and 4-iodoaniline (Fluka, 98\%) were recrystallized twice from petroleum ether (bp $35-80^{\circ} \mathrm{C}$ ), and 4-chloroaniline (Fluka, 99\%) was used without further purification. Methylviologen $\left(1,1^{\prime}\right.$-dimethyl-4,4'-bipyridinium dichloride trihydrate, $\mathrm{MV}^{2+}$ ) from Fluka $(>98 \%)$ was recrystallized from methanol/methylene chloride/ cyclohexane $(1 / 10 / 10)$. The disodium salt of ethylenediaminetetraacetic acid (EDTA dihydrate, Merck, p.a.) was recrystallized from methanol/water as described in the literature. ${ }^{25}$ Solvents used were demineralized water and ethylene glycol (Merck, p.a.).

2.2. Instrumentation. The nanosecond laser flash equipment has been described in a previous paper. ${ }^{6}$ Coumarin 2 was used as laser dye to obtain a wavelength of $450 \mathrm{~nm}$ for exciting the ruthenium complexes. The continuous-flow technique is described in detail in ref 26 . The setup used here is basically the same, except for the flow-through cuvette used for photolysis (optical path length 0.1 instead of $1 \mathrm{~cm}$ ) and the spectrometer which was replaced by an Isco $\mathrm{V}^{4}$ absorbance detector equipped with a $5-\mathrm{mm}$ preparative flow cell. The principle of operation is described in section 3.1. Stationary irradiation experiments were carried out with a conventional setup, using a $200-\mathrm{W}$ high-pressure mercury lamp; absorption spectra were recorded on a Perkin-Elmer Lambda 5 spectrophotometer.

2.3. Specific Conditions. For the laser experiments the concentrations of the complexes were $2 \times 10^{-5} \mathrm{M}$ in water. The samples were deaerated by purging with solvent-saturated suprapure $\mathrm{N}_{2}$ for $45 \mathrm{~min}$. Triplet-triplet absorption was observed at $380 \mathrm{~nm}$ in the case of $\left[\mathrm{Ru}(\mathrm{dce})_{3}\right]^{2+}$ and at $313 \mathrm{~nm}$ for $[\mathrm{Ru}$ (bpy) $]_{3}^{2+}$ and the phosphorescence emission at 620 and $630 \mathrm{~nm}$, respectively. The standard concentrations for the continuous irradiation experiments were $\left[\mathrm{Ru}(\mathrm{bpy})_{3}\right]^{2+}, 2 \times 10^{-5} \mathrm{M} ; \mathrm{MV}^{2+}$, $2.5 \times 10^{-3} \mathrm{M}$; and EDTA, $1 \times 10^{-2} \mathrm{M}$. The $\mathrm{pH}$ of the solutions was adjusted to 6.2 by adding suitable amounts of a $1 \mathrm{M}$ aqueous $\mathrm{NaOH}$ solution. At this $\mathrm{pH}$ EDTA acts as a convenient buffer system $\left(\mathrm{p} K_{\mathrm{a}, 3}=6.16^{27}\right)$. Deaeration was achieved by purging with solvent-saturated suprapure $\mathrm{N}_{2}$ for $90 \mathrm{~min}$, i.e., twice as long as for the laser experiments, because in continuous photolysis the overall quantum yield is much more sensitive to traces of oxygen than in the former case. Mixtures of water and ethylene glycol were used for studying the viscosity dependence of the magnetic field effect.

\section{Results}

3.1. Oxidative Quenching of Photoexcited $\left[R u(b p y)_{3}\right]^{2+}$ by $M V^{2+}$. The kinetics of the reaction between photoexcited [Ru(bpy) $\left.{ }_{3}\right]^{2+}$ and $\mathrm{MV}^{2+}$ has been studied by several groups (cf. ref 28-32). The quenching process is described in Scheme I. After

(22) Broomhead, J. A.; Young, C. G. Inorg. Synth. 1982, 21, 127

(23) Watts, R. J.; Crosby, G. A. J. Am. Chem. Soc. 1971, 93, 3184. (24) Elliott, C. M.; Hershenhart, E. J. J. Am. Chem. Soc. 1982, 104, 7519.

(25) Blaedel, W. J.; Knight, H. T. Anal. Chem. 1954, 26, 741.

(26) Schlenker, W.; Steiner, U. E. Ber. Bunsen-Ges. Phys. Chem. 1985, 89,1041

(27) Bonneau, R.; Joussot-Dubien, J.; Faure, J. Photochem. Photobiol.

$1973,17,313$.

(28) Kalyanasundaram, K. Coord. Chem. Rev. 1982, 46, 159.

(29) Amouyal, E.; Zidler, B.; Keller, P.; Moradpour, A. Chem. Phys. Lett. $1980,74,314$.

(30) Kalyanasundaram, K. Neumann-Spallart, M. Chem. Phys, Lett. 1982, 88, 7

(31) Mandal, K.; Hoffman, M. Z. J. Phys. Chem. 1984, 88, 185

(32) Chiorboli, C.; Indelli, M. T.; Rampi Scandola, M. A.; Scandola, F. J. Phys. Chem. 1988, 92, 156.

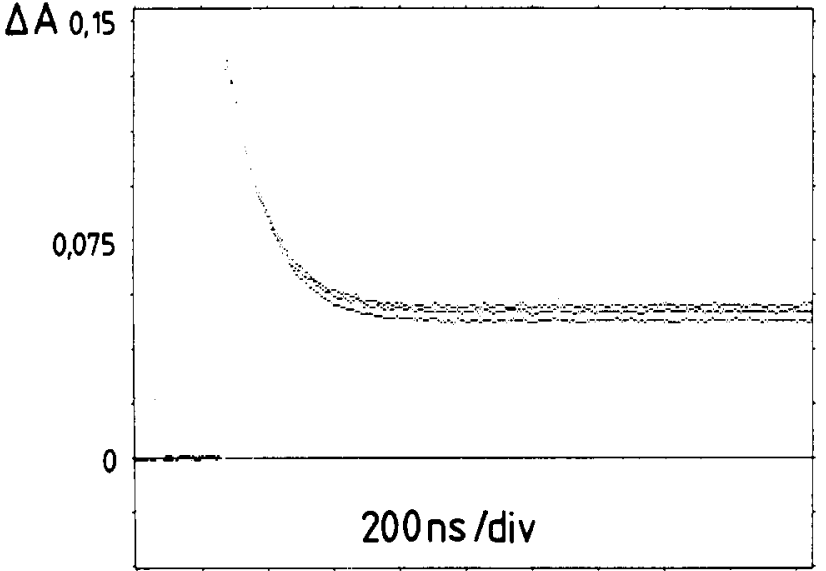

Figure 1. Transient absorption signals observed by laser flash spectroscopy with a deaerated solution of $\left[\mathrm{Ru}(\mathrm{bpy})_{3}\right]^{2+}\left(2 \times 10^{-5} \mathrm{M}\right)$ and $\mathrm{MV}^{2+}$ $\left(10^{-2} \mathrm{M}\right)$. The wavelength of observation is $313 \mathrm{~nm}$. Signals from top to bottom correspond to magnetic fields of $0,0.2$, and $1.0 \mathrm{~T}$.

excitation the complex relaxes to a closely spaced electronic state manifold which is predominantly of triplet origin but strongly contaminated with singlet. ${ }^{33-38}$ Therefore we designate this reacting state manifold by a multiplicity symbol $3^{\prime}$. The excited ${ }^{\prime}\left[\mathrm{Ru}(\mathrm{bpy})_{3}\right]^{2+}$ is quenched with a rate constant $k_{\mathrm{q}}$ for which in aqueous solution values between $4 \times 10^{8}$ and $2.6 \times 10^{9} \mathrm{M}^{-1} \mathrm{~s}^{-1}$ have been reported. The actual value depends on the ionic strength and specific counterion effects. ${ }^{30-32}$ Our own experiments in aqueous solution without any added salts yielded a value between $5 \times 10^{8}$ and $6 \times 10^{8} \mathrm{M}^{-1} \mathrm{~s}^{-1}$ from both absorption and emission techniques. These are in fair agreement with the literature data ${ }^{32}$ for solutions with low ionic strength. For $c_{\mathrm{MY}^{2+}}>5 \times 10^{-3} \mathrm{M}$ the effective decay rate constant $k_{\text {eff }}$ of ${ }^{\prime}\left[\mathrm{Ru}(\mathrm{bpy})_{3}\right]^{2+}$ showed gradually increasing positive deviations from the limiting SternVolmer slope at low concentrations. For example, with $c_{\mathrm{MV}^{2+}}=$ $10^{-2} \mathrm{M}$ a value of $k_{\text {eff }}=8 \times 10^{6} \mathrm{~s}^{-1}$ was observed, whereas a value of $5.8 \times 10^{6} \mathrm{~s}^{-1}$ is extrapolated from the Stern-Volmer slope at low concentrations. This deviation may be readily explained as an effect of increasing ionic strength at the higher concentration of $\mathrm{MV}^{2+} 32$

In the quenching process $\mathrm{MV}^{\bullet+}$ radical ions and $\left[\mathrm{Ru}(\mathrm{bpy})_{3}\right]^{3+}$ ions are generated. However, as was recently reviewed and reinvestigated by Hoffman, ${ }^{41}$ the efficiency $\eta_{\text {net }}$ of net electron transfer is clearly lower than $100 \%$. The exact results depend on the ionic strength of the solution. Although there is some scatter in the published data (e.g., values of $0.25^{30}$ and $0.38^{32}$ were reported for low ionic strength), under no conditions a value higher than 0.5 has been reported. These figures indicate that very

(33) Hipps, K. W.; Crosby, G. A. J. Am. Chem. Soc. 1975, 97, 7042

(34) Kober, E. M.; Meyer, T. J. Inorg. Chem. 1984, 23, 3877.

(35) Hipps, K. W. Inorg. Chem. 1980, 19, 1390.

(36) (a) Felix, F.; Ferguson, J.; Güdel, H. U.; Ludi, A. Chem. Phys. Lett. 1979, 62, 153. (b) Felix, F.; Ferguson, J.; Güdel, H. U.; Ludi, A. J. Am Chem. Soc, 1980, 102, 4096. (c) Decurtins, S.; Felix, F.; Ferguson, J.; Güdel, H. U.; Ludi, A. J. Am. Chem. Soc. 1980, 102, 4102.

(37) (a) Yersin, H.; Gallhuber, E. J. Am. Chem. Soc. 1984, 106, 6582. (b) Yersin, H.; Gallhuber, E.; Hensler, G. Chem. Phys. Lett. 1987, 134, 497. (c) Hensler, G.; Gallhuber, E.; Yersin, H. Inorg. Chem. 1987, 26, 1641. (d) Yersin, H.; Hensler, G.; Gallhuber, E. Inorg. Chim. Acta 1987, 132, 187. (e) Gallhuber, E.; Hensler, G.; Yersin, H. Photochemistry and Photophysics of Coordination Compounds; Yersin, H., Vogler, A., Eds.; Springer: Berlin, 1987; p 93.

(38) Recent observations with excited $\left[\mathrm{Ru}(\mathrm{bpy})_{3}\right]^{2+}$ in low-temperature glassy media probing ODMR and ESR ${ }^{39}$ or emission polarization spectra ${ }^{40}$ have been interpreted in favor of a single spin triplet emitting state. However, no electronic model to reconcile this suggestion with the strong spin-orbit coupling effects to be expected from the MLCT nature of the emitting state has been provided. 197.

39) Yamauchi, S.; Komada, Y.; Hirota, N. Chem. Phys. Lett. 1986, 129

(40) Myrick. M. L.; DeArmond, M. K.; Blakley, R. L. Chem. Phys. Lett., in press; Abstracts of Papers, XII IUPAC Symposium on Photochemistry, Bologna, 1988; p 309

(41) Hoffman, M. Z. J. Phys. Chem. 1988, 92, 3458. 


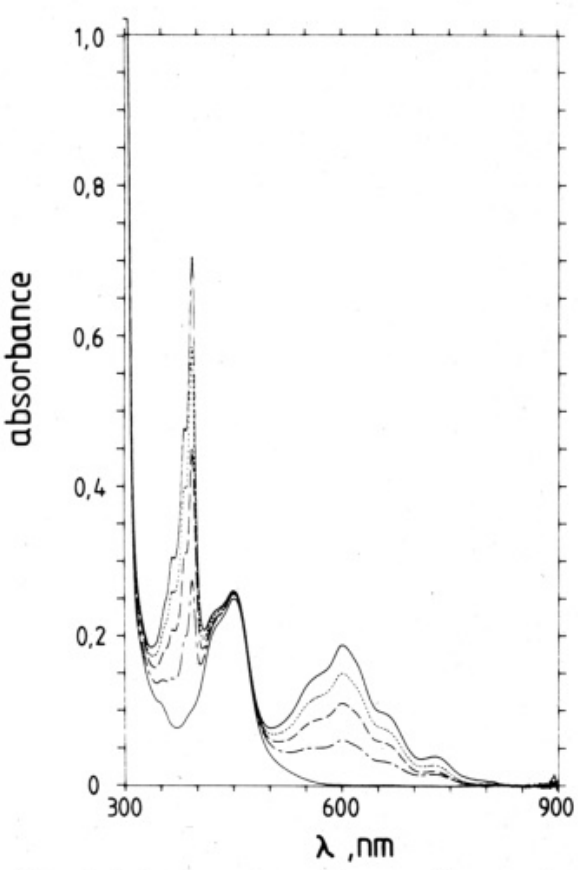

Figure 2. Spectral changes observed on continuous photolysis of a deaerated solution of $\left[\mathrm{Ru}(\mathrm{bpy})_{3}\right]^{2+}\left(2 \times 10^{-5} \mathrm{M}\right), \mathrm{MV}^{2+}\left(2 \times 10^{-3} \mathrm{M}\right)$, and EDTA $\left(10^{-2} \mathrm{M}\right)$. The spectra from bottom to top were observed at intervals of $10 \mathrm{~s}$ irradiation time. The wavelength of irradiation was 437 $\mathrm{nm}$.

efficient BET must take place before the products of the forward electron transfer can separate.

In order to follow the triplet decay and detect the relative magnetic field effect on the yield of net electron transfer, we found it convenient to observe the laser-induced transient absorption at a wavelength of $313 \mathrm{~nm}$, the second maximum of the $\Delta A$ spectrum of ${ }^{3^{\prime}}\left[\mathrm{Ru}(\mathrm{bpy})_{3}\right]^{2+} \cdot{ }^{42,43}$ At this wavelength the absorbance of the redox products is also appreciable, ${ }^{44,45}$ giving a positive $\Delta A$ signal, however, weaker than that of the triplet. Thus, when moderate concentrations of $\mathrm{MV}^{2+}$ are used, the triplet decay can still be observed after the laser pulse (fwhm $15 \mathrm{~ns}$ ) and the plateau reached after complete triplet decay is a linear measure of the net electron transfer efficiency. ${ }^{46}$

The quencher concentration used in the example of signals shown in Figure 1 was $10^{-2} \mathrm{M}$ with a corresponding first-order decay constant $k_{\text {eff }}=8 \times 10^{6} \mathrm{~s}^{-1}$ for ${ }^{3}\left[\mathrm{Ru}(\mathrm{bpy})_{3}\right]^{2+}$. The signal traces shown were recorded with magnetic fields of $0,0.2$, and $1.0 \mathrm{~T}$. Each curve represents an average of 64 single-shot responses. The reproducibility of the signal amplitudes was about $\pm 1 \%$, yielding a clear statistical significance of the following magnetic field effect values for the radical yield: $-4 \%$ at $0.2 \mathrm{~T}$ and $-10 \%$ at $1.0 \mathrm{~T}$. However, when dealing with such small absorbance changes, the accuracy of the time-resolved experiment was not sufficient to warrant a precise determination of the details of the magnetic field dependence of this effect.

Fortunately, in this reaction system the short-time information on the yield of free radicals can be preserved for slower but more precise detection methods by the use of EDTA as a sacrificial donor, intercepting the $\left[\mathrm{Ru}(\mathrm{bpy})_{3}\right]^{3+}$ complexes and thus preventing the $\mathrm{MV}^{\bullet+}$ radicals from reoxidation. This method is

(42) Lachish, U.; Infelta, P. P.; Grätzel, M. Chem. Phys. Lett. 1979, 62, 317.

(43) Hauser, A.; Krausz, E. Chem. Phys. Lett. 1987, 138, 355.

(44) Watanabe, T.; Honda, K. J. Phys. Chem. 1982, 86, 2617.

(45) McCaffery, A. J.; Mason, S. F.; Norman, B. J. J. Chem. Soc. A 1969, 1428.

(46) From spectral changes in the 3-80- $\mu$ s time domain Ferraudi and Argüello concluded that the CT products found in the quenching might remain associated for such a period before finally dissociating into free $\left[\mathrm{Ru}(\mathrm{bpy})_{3}\right]^{3+}$ and $\mathrm{MV}^{*+}$. We think that this interpretation is very hard to accept since it is known that the bimolecular rate constant of recombination of $\left[\mathrm{Ru}(\mathrm{bpy})_{3}\right]^{3+}$ and $\mathrm{MV}^{*+}$ is about $(3-5) \times 10^{-9} \mathrm{M}^{-1} \mathrm{~s}^{-1}$, 21 i.e., close to diffusion controlled. Therefore, any associate between them ought to be very short-lived.
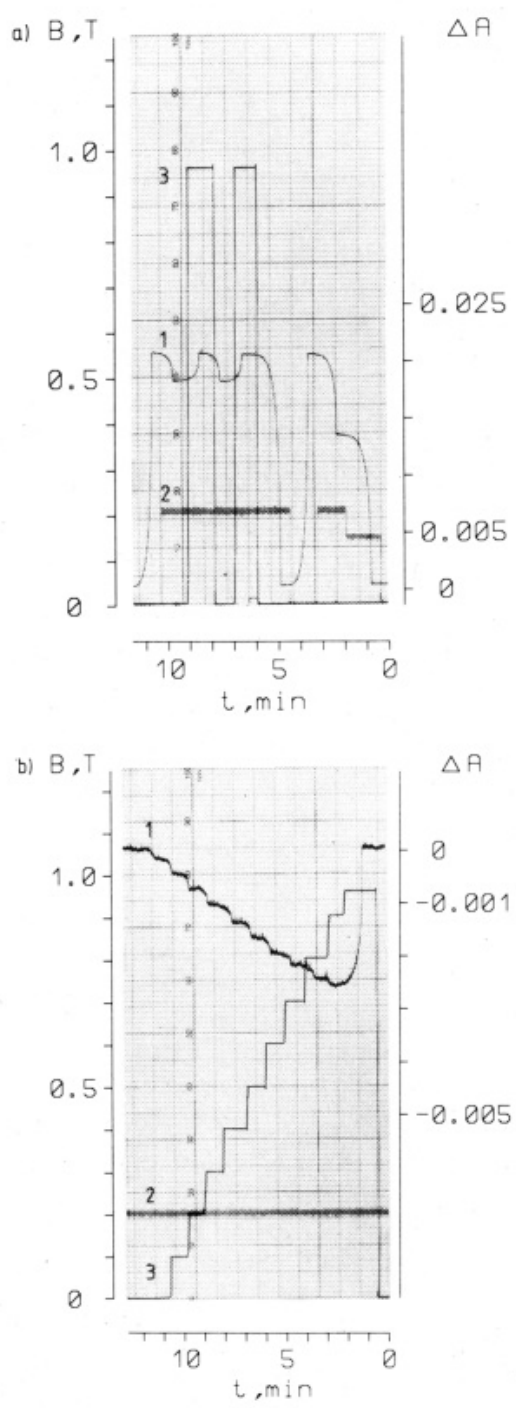

Figure 3. Signal traces from the continuous-flow experiments applying magnetic field steps during continuous illumination: (1) absorbance detected at $600 \mathrm{~nm}$ in the second flow-through cuvette; (2) fluence of photolyzing light in the first flow-through cuvette, in arbitrary units; (3) magnetic field strength at first flow-through cuvette. Parts a and b of the figure are examples recorded at different sensitivities of the UV detector.

well-known from research work devoted to the design of chemical systems that are capable of direct photochemical water splitting. ${ }^{28,47}$ The production of $\mathrm{MV}^{\bullet+}$ radicals during continuous photolysis of such a system may be followed by conventional UV spectroscopy (cf. Figure 2). Thus, with this chemical modification, we were able to apply our previously developed equipment utilizing a stepwise magnetic field modulation of continuous-flow steadystate photolysis, ${ }^{26}$ which allows for a far better resolution of the magnetic field effects on photochemical quantum yields than the flash spectroscopic method.

The principle of the technique is as follows. The photoreactive solution is irradiated in a flow cuvette positioned between the pole pieces of an electromagnet. When the photolyzing light beam is opened or blocked, the permanent photochemical change may be detected as a steplike absorption change in a subsequent flow-through cuvette positioned in a UV spectrometer recording at a suitable wavelength (cf. Figure 3a). The height of these steps is proportional to the quantum yield of the reaction as long as the relative turnover of the photochemical reactants is small. Switching on and off the magnetic field during the irradiation periods produces analogous steps in the trace of the recorded absorbance signal, if the quantum yield is magnetic field de-

(47) Kalyanasundaram, K. J. Chem. Soc., Chem. Commun. 1978, 628. 


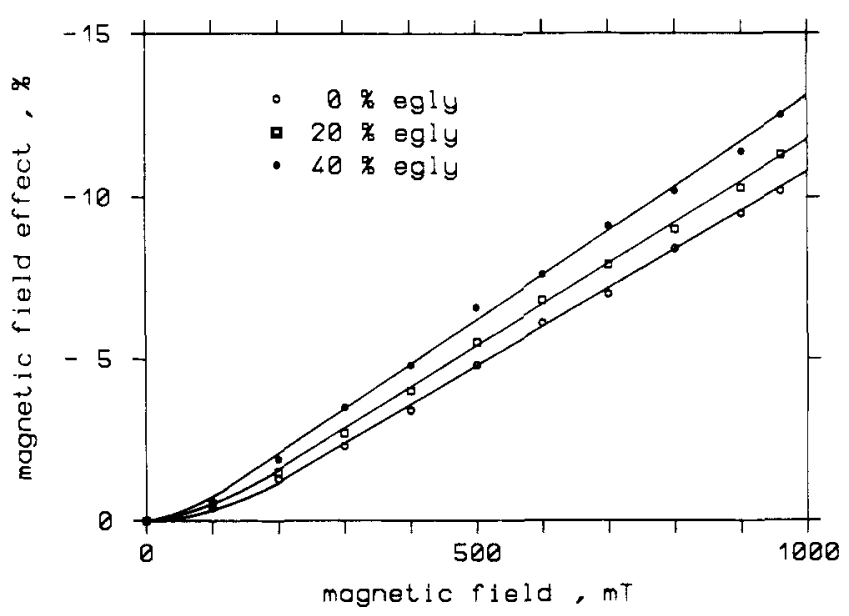

Figure 4. Relative magnetic field effect on the quantum yield of $\mathrm{MV}^{\bullet+}$ production in continuous photolysis of the $\left[\mathrm{Ru}(\mathrm{bpy})_{3}\right]^{2+} / \mathrm{MV}^{2+} / \mathrm{EDTA}$ system for various mixtures of water and ethylene glycol (volume percentage specified) as solvents.

TABLE I: Effect of Solvent Viscosity on Linear Section of Magnetic Field Dependence in the $\left[\mathrm{Ru}(\mathrm{bpy})_{3}\right]^{2+} / \mathrm{MV}^{2+} /$ EDTA System

\begin{tabular}{cccc}
\hline \% ethylene glycol ${ }^{a}$ & viscosity, $\mathrm{cP}$ & B $_{\text {onset, }}{ }^{b} \mathrm{mT}$ & $a,{ }^{b} \mathrm{mT}^{-1}$ \\
\hline 0 & 0.89 & 88 & 1.17 \\
20 & 1.35 & 73 & 1.27 \\
40 & 2.48 & 48 & 1.37
\end{tabular}

a Volume percent of ethylene glycol in mixture with water ${ }^{b}$ Obtained from linear regression $R(B)=a\left(B-B_{\text {onset }}\right)$ using data points at $B>2 B_{\text {onset }}$ only.

pendent. The relative magnetic field effect on the quantum yield is directly obtained from the ratio of these steps to those obtained with irradiation on/off.

As can be seen from Figure 3a, switching on a magnetic field has a similar effect as would have lowering the fluence of the photolyzing light, which means that a magnetic field decreases the quantum yield of $\mathrm{MV}^{++}$formation, in line with the result of the nanosecond laser flash experiments. In Figure $3 \mathrm{~b}$ is shown the change in absorbance produced by the magnetic field, however recording the signal at a sensitivity that is increased by a factor of 5. Furthermore, the magnetic field is varied in small steps and the response of the signal to these is very well resolved. In fact, the signal noise is as low as about $0.3 \%$ of the quantum yield, allowing for a correspondingly high resolution of the magnetic field dependence. The results are shown in Figure 4 where the magnetic field dependence of the quantum yield of $\mathrm{MV}^{\circ+}$ formation is plotted for several water/ethylene glycol mixtures, which have been investigated in order to assess the effect of solvent viscosity. In all of the solvents the magnetic field dependence is of the same shape, which is characterized by a gradual onset of the field dependence at low fields and a linear rise above about $0.1 \mathrm{~T}$ continuing up to $1 \mathrm{~T}$, the highest field investigated in this work. The maximum field effect at $1 \mathrm{~T}$ corresponds to a $10 \%$ decrease of the quantum yield in purely aqueous solution, which compares fa vorably with the results from the laser experiments. The absolute value of this effect increases with solvent viscosity. Characteristic data referring to the linear parts of the magnetic field dependence are listed in Table I. Let us now address the problem how the observed magnetic field effect is related to the kinetic parameters defined in Scheme I. The yield of free radicals $\Phi_{\mathrm{fr}}$ may be expressed as

$$
\Phi_{\mathrm{fr}}=\eta_{\text {net }} \frac{k_{\mathrm{q}}\left[\mathrm{MV}^{2+}\right]}{k_{0}+k_{\mathrm{q}}\left[\mathrm{MV}^{2+}\right]}
$$

demonstrating that a magnetic field effect $R\left(\Phi_{\mathrm{fr}}\right)$ may depend on any of the possible field effects $R\left(\eta_{\text {net }}\right)$ (or equivalently $R\left(\eta_{\text {bet }}\right)$ ), $R\left(k_{\mathrm{q}}\right)$, and $R\left(k_{0}\right)$. Possible magnetic field effects on $k_{0}$ and $k_{\mathrm{q}}$ were checked by observing the magnetic field dependence of the

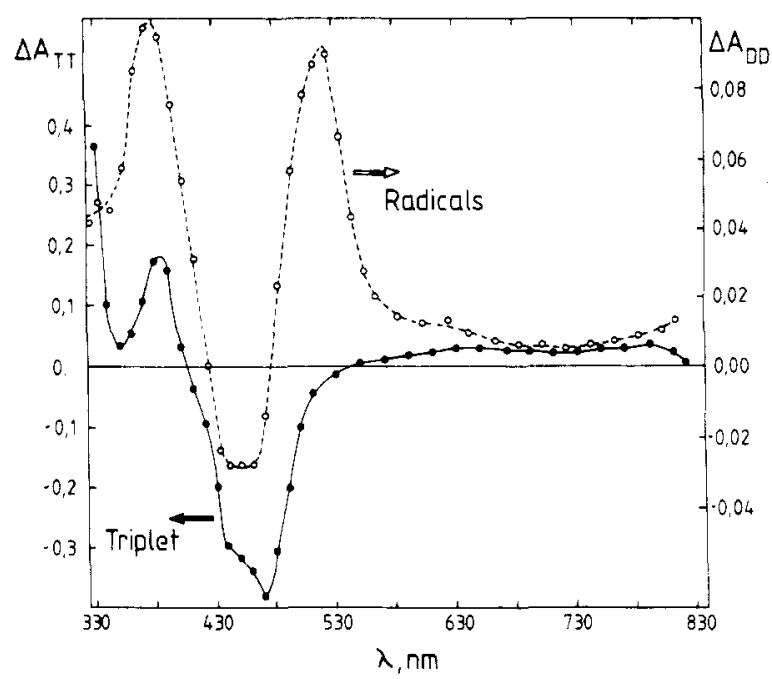

Figure 5. Transient absorption spectra with $\left[\mathrm{Ru}(\mathrm{dce})_{3}\right]^{2+}\left(2 \times 10^{-5} \mathrm{M}\right)$ in water: - - , T-T absorption spectrum, recorded 80 ns after the laser flash; - - - - -, Radical absorption of $\left[\mathrm{Ru}(\mathrm{dce})_{3}\right]^{+} /$aniline $^{*+}$, recorded $4 \mu \mathrm{s}$ after the flash. The concentration of aniline was $2.25 \times 10^{-3} \mathrm{M}$.

decay time $\tau_{\text {eff }}$ of $\left[\mathrm{Ru}(\mathrm{bpy})_{3}\right]^{2+}$ emission. The corresponding rate constant $k_{\text {eff }}\left(\left[\mathrm{MV}^{2+}\right]\right)$ is given by

$$
k_{\text {eff }} \equiv \frac{1}{\tau_{\text {eff }}}=\left(k_{0}+k_{\mathrm{q}}\left[\mathrm{MV}^{2+}\right]\right)
$$

For $\left[\mathrm{MV}^{2+}\right]=0,2.5 \times 10^{-3} \mathrm{M}$, and $7.5 \times 10^{-3} \mathrm{M}$ corresponding to $0 \%, 32 \%$, and $67 \%$ quenching, respectively, the magnetic field effect on $k_{\text {eff }}$ was clearly below $1 \%$, i.e., within the standard deviation of the measurement. This result is at variance with those of Ferraudi and Argüello ${ }^{21}$ who reported $R\left(k_{0}, 1 \mathrm{~T}\right) \approx+3 \%, R\left(k_{\mathrm{q}}, 1\right.$ $\mathrm{T}) \approx-20 \%$.

The various contributions to $R\left(\Phi_{\mathrm{fr}}\right)$ may be also analyzed from the $\left[\mathrm{MV}^{2+}\right.$ ] dependence of $R\left(\Phi_{\mathrm{fr}}\right)$. Expressing a change $\mathrm{d} \Phi_{\mathrm{fr}}$ in $\Phi_{\mathrm{fr}}$ as the differential with respect to differential changes in $\eta_{\text {net }}$, $k_{0}$, and $k_{\mathrm{q}}$, we can derive the expression

$$
\frac{\mathrm{d} \Phi_{\mathrm{fr}}}{\Phi_{\mathrm{fr}}}=\frac{\mathrm{d} \eta_{\text {net }}}{\eta_{\text {net }}}+\left(\frac{\mathrm{d} k_{\mathrm{q}}}{k_{\mathrm{q}}}-\frac{\mathrm{d} k_{0}}{k_{0}}\right) \frac{k_{0}}{k_{0}+k_{\mathrm{q}}\left[\mathrm{MV}^{2+}\right]}
$$

For small magnetic field effects the normalized differentials correspond to the relative field effects $R\left(\Phi_{\mathrm{fr}}\right), R\left(\eta_{\text {net }}\right), R\left(k_{0}\right)$, and $R\left(k_{\mathrm{q}}\right)$, respectively, i.e.

$$
R\left(\Phi_{\mathrm{fr}}\right)=R\left(\eta_{\mathrm{net}}\right)+\left(R\left(k_{\mathrm{q}}\right)-R\left(k_{0}\right)\right) \frac{k_{0}}{k_{0}+k_{\mathrm{q}}\left[\mathrm{MV}^{2+}\right]}
$$

Thus, measuring $R\left(\Phi_{\mathrm{fr}}\right)$ as a function of $\left[\mathrm{MV}^{2+}\right]$ will allow separation of the effects $R\left(\eta_{\text {net }}\right)$ and $\left(R\left(k_{\mathrm{q}}\right)-R\left(k_{0}\right)\right)$. The [MV ${ }^{2+}$ ] dependence of $R\left(\Phi_{f r}\right)$ was checked for three concentrations $\left(\left[\mathrm{MV}^{2+}\right]=10^{-3}, 2.5 \times 10^{-3}, 10^{-2} \mathrm{M}\right)$ at a field of $1 \mathrm{~T}$, yielding $R\left(\Phi_{\mathrm{fr}}, 1 \mathrm{~T}\right)=-9.7 \%,-10.3 \%$, and $-10.7 \%$, respectively. A linear regression with these values based on eq 4 yields $R\left(\eta_{\text {net }}\right)=-11.3 \%$ and $R\left(k_{\mathrm{q}}\right)-R\left(k_{0}\right)=2 \%$. Thus, again, these experiments demonstrate that the magnetic field effect is essentially due to $R\left(\eta_{\text {net }}\right)$ and not to $R\left(k_{\mathrm{q}}\right)$ as suggested by Ferraudi and Argüello.

3.2. Reductive Quenching of Photoexcited $\left[R u(d c e)_{3}\right]^{2+}$ by Anilines. In order to assess the role of SOC on overall photoelectron-transfer efficiencies, i.e., on the net effect of forward and fast backward electron transfer, with $\mathrm{Ru}^{\mathrm{II}}$ complexes of the trisbipyridyl type, we applied a series of haloanilines including aniline itself as electron donors because with these we previously had been able to quantify SOC effects in other photoelectrontransfer reactions. ${ }^{9.18}$ Since the anilines have oxidation potentials of about $0.9 \mathrm{~V}$ (vs SCE in acetonitrile), ${ }^{48}$ they do not quench ${ }^{\prime}\left[\mathrm{Ru}(\mathrm{bpy})_{3}\right]^{2+}\left(E^{*}{ }_{\text {red }}=0.77 \mathrm{~V} \text { vs SCE in acetonitrile }\right)^{28}$ efficiently. 
TABLE II: Reaction Data for the Quenching of ${ }^{3}\left[R u(d c e)_{3}\right]^{2+}$ by Various Anilines

\begin{tabular}{lllc}
\hline donor & $k_{\mathrm{q}}, \mathrm{M}^{-1} \mathrm{~s}^{-1}$ & $\eta^{\prime}{ }_{\text {net }}^{a}$ & $\left.\eta_{\text {net }}{ }^{3} \mathrm{TH}^{+}\right)^{b}$ \\
\hline aniline & $2.5 \times 10^{9}$ & 1.0 & 1.0 \\
$4-\mathrm{Cl}$ & $2.6 \times 10^{9}$ & 0.79 & 0.97 \\
$4-\mathrm{Br}$ & $3.0 \times 10^{9}$ & 0.45 & 0.52 \\
$2-\mathrm{I}$ & $1.4 \times 10^{9}$ & 0.22 & 0.23 \\
$4-\mathrm{I}$ & $3.0 \times 10^{9}$ & 0.12 & 0.14
\end{tabular}

${ }^{a}$ Relative values in comparison to aniline, which has an absolute value of about 0.4 (cf. text). ${ }^{b}$ Absolute values for the corresponding reactions of triplet thionine, from ref 52 .

Therefore, we used $\left[\mathrm{Ru}(\mathrm{dce})_{3}\right]^{2+}$, which is a much better photooxidant $\left(E_{\text {red }} \approx 1.14 \mathrm{~V}\right)$. $^{49}$

Spectra of absorbance changes observed on flashing aqueous solutions of $\left[\mathrm{Ru}(\mathrm{dce})_{3}\right]^{2+}$ without a quencher and with aniline as electron donor are shown in Figure 5. Whereas the first one corresponds to the ${ }^{3^{\prime}}\left[\mathrm{Ru}(\mathrm{dce})_{3}\right]^{2+} /\left[\mathrm{Ru}(\mathrm{dce})_{3}\right]^{2+}$ difference spectrum, the second one pertains to the $\left(\left[\mathrm{Ru}(\mathrm{dce})_{3}\right]^{+}+\right.$aniline $\left.^{*+}\right) /\left(\left[\mathrm{Ru}(\mathrm{dce})_{3}\right]^{2+}+\right.$ aniline $)$ case. Both spectra exhibit a similar weak and broad absorption at long wavelengths extending to the near-infrared. This band probably results from exciting the reduced ligand dce ${ }^{\circ}$, which is formed as a result of the MLCT excitation in the former case and as a result of electron transfer from the quencher in the latter. Analogous assignments have been made for $\left[\mathrm{Ru}(\mathrm{bpy})_{3}\right]^{2+43}$ and $\left[\mathrm{Ru}\left(2,2^{\prime} \text {-bipyrazine }\right)_{3}\right]^{2+} .50$

Our kinetic experiments and determinations of yields of net electron transfer were made at $380 \mathrm{~nm}$ where both triplet and radical absorption spectra exhibit maxima. From extrapolating the observed transient absorbance values to complete conversion at high laser energy, we estimated as an upper limit for the difference of molar extinction coefficients $\Delta \epsilon_{380}$ (triplet) $=\epsilon_{380^{-}}$ $\left({ }^{\prime}\left[\mathrm{Ru}(\text { dce })_{3}\right]^{2+}\right)-\epsilon_{380}\left(\left[\mathrm{Ru}(\text { dce })_{3}\right]^{2+}\right)=(11500 \pm 15 \%) \mathrm{M}^{-1} \mathrm{~cm}^{-1}$. For the conversion $\left[\mathrm{Ru}(\mathrm{dce})_{3}\right]^{2+} \rightarrow\left[\mathrm{Ru}(\mathrm{dce})_{3}\right]^{+}$a $\Delta \epsilon$ of $(20800$ $\pm 10 \%) \mathrm{M}^{-1} \mathrm{~cm}^{-1}\left(\lambda_{\max }=538 \mathrm{~nm}\right.$, solvent DMF) can be taken from the work of Elliott and Hershenhart. ${ }^{24}$ Assuming that this value is unchanged for the corresponding spectral maximum in water $\left(\lambda_{\max }=510 \mathrm{~nm}\right)$ and using the fact that the contributions of aniline and the aniline cation radical to $\Delta \epsilon$ are negligible at this wavelength, ${ }^{51}$ we may normalize our $\Delta A$ spectrum (cf. Figure 5) that corresponds to the conversion $\left[\mathrm{Ru}(\mathrm{dce})_{3}\right]^{2+}+$ aniline $\rightarrow$ $\left[\mathrm{Ru}(\mathrm{dce})_{3}\right]^{+}+$aniline $^{*+}$ to absolute $\Delta \epsilon$ values over the complete spectral range. A value of $\Delta \epsilon_{380}$ (radicals) $=(22400 \pm 35 \%) \mathrm{M}^{-1}$ $\mathrm{cm}^{-1}$ is obtained whereby, to be on the safe side, the error margin has been considerably increased to account for the uncertainty arising from the comparison of different solvents.

The rate constants $k_{\mathrm{q}}$ of ${ }^{3^{\prime}}\left[\mathrm{Ru}(\mathrm{dce})_{3}\right]^{2+}$ quenching by various anilines and the relative yields $\eta_{\text {net }}^{\prime}$ of net electron transfer as determined by ns-laser flash spectroscopy are listed in Table II. With the molar extinction coefficients quoted above, the absolute yield of net electron transfer with aniline is obtained as $40 \pm 20 \%$.

As can be noted from these data, there is no specific heavy-atom effect on the rate constant $k_{\mathrm{q}}$ in the series of haloanilines. There is, however, a systematic decrease of the radical yield as the nuclear charge of the substituents increases. Note that there is also a position dependence of this effect which is borne out by the results for the two iodoanilines. Attempts have been made at observing magnetic field effects on the efficiency of overall electron transfer $\eta_{\text {net }}$ in these systems. Only in the case where 4-iodoaniline was used as a quencher could a statistically significant effect be assessed. In Figure 6 is shown a corresponding transient absorption signal detected at $380 \mathrm{~nm}$. With a donor concentration of $2 \times$ $10^{-3} \mathrm{M}$ the transient absorption decays within about $300 \mathrm{~ns}$ to a constant plateau which is a measure of the amount of [Ru-

(49) Wacholtz, W. F.; Auerbach, R. A.; Schmehl, R. H. Inorg. Chem. 1986, 25, 227.

(50) Ohno, T. J. Phys. Chem., in press.

(51) (a) Qin, L.; Tripathi, G. N. R.; Schuler, R. H. Z. Naturforsch. 1985, 40a, 1026. (b) Shida, T.; Nosaka, Y.; Kato, T. J. Phys. Chem. 1978, 82, 695.

(52) The original results reported in ref 18 have been slightly revised by: Waschi, H. P. Doctoral Thesis, Universität Stuttgart, 1983. Values from the latter work are quoted in Table II.

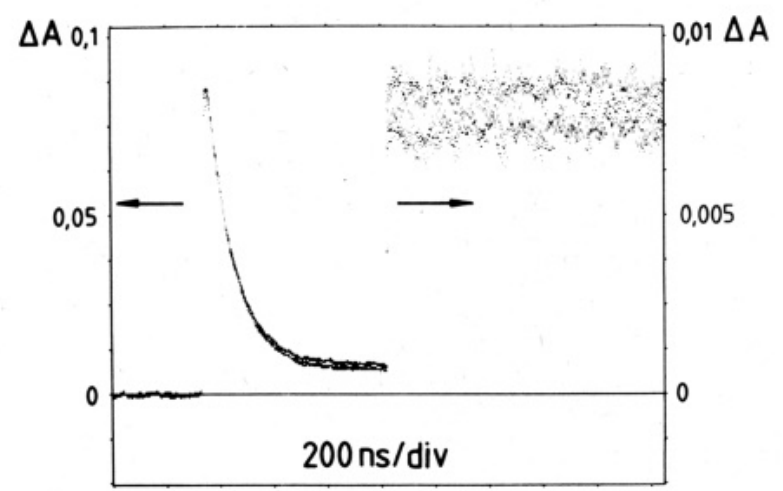

Figure 6. Magnetic field effect on the radical yield in the quenching of ${ }^{\prime}\left[\mathrm{Ru}(\mathrm{dce})_{3}\right]^{2+}$ by 4 -iodoaniline $\left(2 \times 10^{-3} \mathrm{M}\right)$. The transient absorption signal was observed at $380 \mathrm{~nm}$. A superposition of eight signal traces is shown, four at zero field (higher radical yield) and four at a magnetic field of $1 \mathrm{~T}$ (lower radical yield). The absorbance is displayed at higher resolution in the second half of the diagram.

$\left.(\text { dce })_{3}\right]^{+}$produced. The figure shows a superposition of eight independently measured signals, each of them an average of 64 single shot traces. Four of the signals were recorded at zero field and four of them at a magnetic field of $1.0 \mathrm{~T}$. In the second half of the diagram the ordinate scale is expanded to show more clearly the statistical significance of the result. In fact, all of the four traces corresponding to one value of the magnetic field join to one closely overlapping set and there is no significant overlap between the signal groups corresponding to different fields. The relative magnetic field effect corresponds to a $10-15 \%$ decrease in overall electron transfer efficiency at a field of $1.0 \mathrm{~T}$. Again, it would be desirable to obtain the magnetic field dependence in some detail. The chemical translation of the radical yield into long-lived products is, however, less straightforward in this case, so that the more accurate continuous mode of detecting photochemical magnetic field effects has not been applied so far.

\section{Discussion}

The experimental results described in the last section demonstrate that the net efficiency of electron transfer in redox reactions of photoexcited complexes of the $\left[\mathrm{Ru}(\mathrm{bpy})_{3}\right]^{2+}$ type may be decreased by a magnetic field and by increasing the SOC strength in the second reactant involved. From this observation one can conclude that a considerable amount of triplet character must be transferred from the photoreactive state to the primary pair of electron-transfer products $\left(\left\{\left[\mathrm{Ru}(\mathrm{bpy})_{3}\right]^{3+} \ldots \mathrm{MV}^{\bullet+}\right\}\right.$ or $\{[\mathrm{Ru}-$ $\left.\left.(\text { dce })_{3}\right]^{+\ldots} \mathrm{Q}^{*+}\right\}$ in the following denoted as "radical pair") and that the triplet/singlet conversion of this pair must be slow enough that an increase of SOC or a magnetic field can affect the overall rate of BET, whereby the singlet ground-state reactants are regenerated.

We presume that in both the oxidative and the reductive quenching the magnetic field effect results from the anisotropic SOC properties of the radical pairs. ${ }^{53}$ However, comparing the oxidative and reductive quenching process, there seems to be a basic difference with respect to a magnetic field sensitivity: in the oxidative process no enhanced SOC is necessary on the side of the second reactant $\left(\mathrm{MV}^{2+}\right)$ to produce the magnetic field effect, whereas only with reactants of greatly enhanced SOC (4-iodoaniline) significant magnetic field effects are observed in the case of the reductive process. In the latter case the SOC properties of the $\left[\mathrm{Ru}(\mathrm{dce})_{3}\right]^{+}$species are obviously not sufficient to cause a magnetic-field-induced increase of the rate of BET. An explanation of this behavior follows from the fact that the [Ru$\left.(\mathrm{dce})_{3}\right]^{+}$species has an electron configuration corresponding essentially to $\left[\mathrm{Ru}(\mathrm{dce}){ }_{2} \mathrm{dce}^{--}\right]^{+}$with the additional electron in the

(53) Triplet to singlet transitions due to hyperfine-coupling-induced spin motion may be neglected. Such a mechanism would be borne out by a positive magnetic field effect on the efficiency of net electron transfer. It would saturate at several tens of gauss and would probably not exceed the order of $1 \%$ because the cage lifetime of RPs with equally charged radicals is too short. 


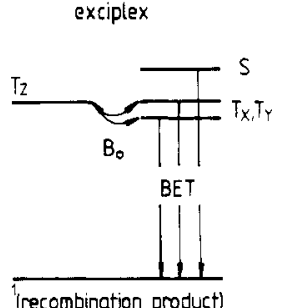

a

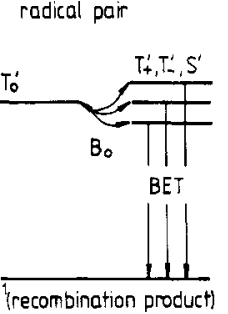

b radical pair

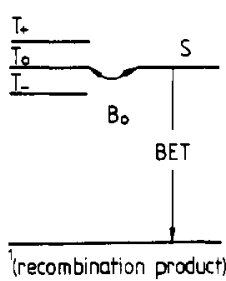

C
Figure 7. Mechanistic cases of SOC induced magnetokinetic effects: (a) triplet mechanism; (b) case of a radical pair involving a strongly spinorbit coupled Kramers doublet; (c) $\Delta g$ mechanism in a normal radical pair.

lowest ligand $\pi^{*}$ orbital. $^{24}$ Thus no particular SOC effects due to the ruthenium core are exhibited, which is also borne out in the $g$ factor measured for $\left[\mathrm{Ru}(\mathrm{bpy})_{2} \mathrm{dce}^{*-}\right]^{+}$as $2.001 .^{54}$

When increasing the SOC strength in the electron donor by going through the series of haloanilines applied here, there is a very marked decrease in the efficiency of net electron transfer, pointing to a corresponding increase in the BET rate. Interestingly, the quantitative results are very similar to those with triplet thionine as an electron acceptor (cf. Table II), which we have related to specific SOC properties of the oxidized haloaniline radicals. ${ }^{18}$ In that case, too, a magnetic field effect on the free-radical yield was observed $(-18 \%$ at $1 \mathrm{~T}$ with 4 -iodoaniline) which was the more pronounced the stronger the SOC effect on the absolute yield of radicals had been. ${ }^{9}$ An explanation has been provided in terms of the triplet mechanism, assuming that SOC in the halogen-substituted donor radicals can directly induce spin-inverted BET. The local symmetry at the halogen substituent has been shown to be responsible for a triplet substate selectivity of this process which disappears in an external magnetic field. From the similarity of the halogen heavy-atom effect in the present case and in the case of thionine triplet quenching, it may be concluded that the same mechanism is effective.

The only significant difference may be found in the initial spin distribution in the primary radical pair, where we have pure triplet spin in the thionine case, but probably significant singlet contamination in the $\left[\mathrm{Ru}(\mathrm{dce})_{3}\right]^{2+}$ case. Thus with aniline, where no special SOC effects can be expected, the efficiency of freeradical formation is 1.0 in the former case but ca. 0.4 in the latter, indicating that appreciable BET takes place.

A kinetic scheme illustrating the mechanism by which SOC and magnetic field cooperate to induce BET in the $[\mathrm{Ru}$ $\left.(\text { dce })_{3}\right]^{+} /$haloaniline ${ }^{++}$pair is depicted in Figure 7a. Even though $\mathrm{S}$ and $\mathrm{T}$ spin states of the pair may be nearly degenerate, SOC in the haloaniline radical cannot mix these states directly since they are of the same orbital origin. On the other hand, spin relaxation in the haloaniline radical, which would also provide a S/T conversion mechanism of the pair, is too slow to achieve such a spin conversion during the cage lifetime of the pair (cf. ref 6 , where the spin relaxation time for the 4-iodoaniline radical was estimated as $\sim 10^{-7} \mathrm{~s}$ ). In line with the triplet mechanism we suggest that, in a contact of the two radicals, SOC in the halogen substituent induces direct spin-inverted BET, a process that is expected to depend on the orientation of the electron spin relative to the local axes of symmetry of the halogen atom site. Therefore, in Figure 7a only BET transitions from $\mathrm{T}_{x}$ and $\mathrm{T}_{y}$ are indicated. The role of the magnetic field is to provide for the transitions $\mathrm{T}_{z} \rightarrow \mathrm{T}_{x y}$ leading to an overall increase of $\mathrm{BET}$.

Let us now consider the case of oxidative quenching of ${ }^{3}[\mathrm{Ru}-$ (bpy) $\left.]_{3}\right]^{2+}$ by $\mathrm{MV}^{2+}$. In the primary radical pair $[\mathrm{Ru}$ (bpy) $\left.]_{3}\right]^{3+} / \mathrm{MV}^{\circ+}$ strong SOC is exhibited by the $\left[\mathrm{Ru}(\mathrm{bpy})_{3}\right]^{3+}$ moiety only. This is borne out by the corresponding $g$ factor, which for $\mathrm{MV}^{*+}$ is in the range $2.003-2.004,55$ close to that of a free electron, whereas for $\left[\mathrm{Ru}(\mathrm{bpy})_{3}\right]^{3+}$ the $\mathrm{g}$-tensor components $\left(g_{\|}\right.$

(54) Gex, J. N.; Cooper, J. B.; Hanck, K. W.; DeArmond, M. K. J. Phys Chem. 1987, $91,4686$.

(55) Rieger, A. L.; Rieger, P. H. J. Phys. Chem. 1984, 88, 5845.
TABLE III: Characteristic Transition Times for Magnetic-Field-Induced Processes in the $\left[\mathrm{Ru}(\mathrm{bpy})_{3}\right]^{3+} / \mathrm{MV}^{\bullet+}$ Pair

\begin{tabular}{cccc}
\hline $\begin{array}{c}\text { orientation of } \\
\text { magnetic field }\end{array}$ & process & $\begin{array}{c}\text { transition time } \\
\text { for } \mathbf{B}_{\mathbf{0}}=1 \mathrm{~T}^{b} \mathrm{ps}\end{array}$ & $\boldsymbol{g}_{\|}$ \\
\hline $\mathbf{B}_{0} \perp z$ & $\mathrm{~T}^{\prime}{ }_{0} \rightarrow \mathrm{T}^{\prime}{ }^{ \pm}$ & 7 & \pm 1.14 \\
$\mathbf{B}_{\mathrm{o}} \| z$ & $\mathrm{~T}^{\prime}{ }_{0} \rightarrow \mathrm{S}^{\prime}$ & 11.3 & -1.14 \\
& & 41.5 & +1.14
\end{tabular}

${ }^{a}$ Orientation of magnetic field relative to trigonal axis $(z)$ of the $\mathrm{Ru}$ complex. ${ }^{b}$ Under static conditions the process corresponds to a coherent oscillation between the states indicated. The value given is the time required for one full conversion.

$\left.=( \pm) 1.14, g_{\perp}=2.64\right)^{56,57}$ indicate strong contributions of orbital magnetism. This conclusion is not affected by a controversy in the literature concerning the sign of $g_{\|}$. The original assignment of a positive value by DeSimone and Drago $^{57}$ has been revised by Kober and Meyer, ${ }^{56}$ who provided good arguments that the negative sign is physically more reasonable.

As follows from the $\mathrm{g}$ tensor, the ground state of $\left[\mathrm{Ru}(\mathrm{bpy})_{3}\right]^{3+}$ must be described as a strongly spin-orbit mixed Kramers doublet entailing about equal contributions of $\alpha$ and $\beta$ spin. ${ }^{33,56}$ The consequence of such strong SOC in one radical on the overall electronic spin of a radical pair has been analyzed in detail by one of the present authors and will be published elsewhere. ${ }^{58}$ Only a brief summary is given here.

Denoting the components of the Kramers doublet that have the effective spin quantized along the trigonal axis of the $\left[\mathrm{Ru}(\mathrm{bpy})_{3}\right]^{3+}$ complex as $\alpha^{\prime}$ and $\beta^{\prime}$, one can construct in the usual way the formal spin states $\mathrm{T}_{0}^{\prime}, \mathrm{T}_{+}^{\prime}, \mathrm{T}_{-}^{\prime}$, and $\mathrm{S}^{\prime}$ of the radical pair. (One should note that the axis of quantization of the effective spin in $\mathrm{T}_{0}^{\prime}$ and $\mathrm{T}^{\prime}{ }_{ \pm}$is defined by the trigonal symmetry axis of the Ru complex.) As the analysis shows, only $\mathrm{T}_{0}^{\prime}$ is a pure $|S|=1$ state, whereas $\mathrm{T}^{\prime}{ }_{ \pm}$and $\mathrm{S}^{\prime}$ are singlet/triplet mixtures with $25 \%(7.3 \%)$ and $50 \%$ $(85.4 \%)$ singlet character, respectively. The values given in parentheses are obtained if the positive sign of $g_{\|}$is used. It is noteworthy that no pure singlet state of the radical pair may be constructed from the basis $\alpha^{\prime} \alpha, \alpha^{\prime} \beta, \beta^{\prime} \alpha, \beta^{\prime} \beta$ of radical pair spin states since three different orbital configurations are involved in this four-state manifold of the radical pair.

The particular distribution of singlet character allows BET for the three radical pair states $T^{\prime}{ }_{ \pm}$and $S^{\prime}$ (cf. Figure $7 \mathrm{~b}$ ). From $T^{\prime}{ }_{0}$ transitions to $\mathrm{T}^{\prime}{ }_{ \pm}$and $\mathrm{S}^{\prime}$ are possible by rotation of the Ru complex and by Zeeman interaction in a magnetic field. For the former, magnetic-field-independent mechanism a rate constant of $3 \times 10^{9}$ $\mathrm{s}^{-1}\left(4.3 \times 10^{8} \mathrm{~s}^{-1}\right.$ if the positive value of $g_{\|}$is used $)$was estimated. ${ }^{58}$ This value is on the order of, or somewhat smaller than, the rate constant of dissociation of the radical pair, for which a value of $\sim 5 \times 10^{9} \mathrm{~s}^{-1}$ may be estimated by the Debye-Eigen expression (cf. recent work on the $\left[\mathrm{Ru}(\mathrm{bpy})_{3}\right]^{3+} / \mathrm{MV}^{\bullet+}$ pair $^{32,41}$ ). Thus, it is to be expected that an acceleration of the $\mathrm{T}^{\prime}{ }_{0} \rightarrow \mathrm{T}^{\prime}{ }_{ \pm}, \mathrm{S}^{\prime}$ process will indeed enhance the efficiency of BET.

A magnetic field, too, induces both types of transitions, $T_{0}^{\prime} \rightarrow$ $\mathrm{S}^{\prime}$ and $\mathrm{T}_{0}^{\prime} \rightarrow \mathrm{T}_{ \pm}^{\prime}$, whereby the former case is the analogue of the well-known $\Delta g$ mechanism of classical radical-pair theory (cf. Figure $7 \mathrm{c}$ ) and the latter is of the type known from the triplet mechanism $^{9,10}$ (cf. Figure $7 \mathrm{a}$ ). Thus the situation in a radical pair involving a strongly spin-orbit coupled Kramers doublet represents a hybrid of the classical radical-pair mechanism and the triplet mechanism.

To give a satisfactory account of the magnetic field effect on the efficiency of BET, one has to resort to a solution of the combined dynamical problem comprising spin transitions under the influence of molecular rotation and a magnetic field, singlet-selective BET, and radical-pair dissociation. At present the full solution to this complex problem is not yet available, but we have determined the magnetic field effect on $\mathrm{T}_{0}^{\prime} \rightarrow \mathrm{T}^{\prime}{ }_{ \pm}, \mathrm{S}^{\prime}$ transitions for various static orientations of the $\mathrm{Ru}$ complex relative to the magnetic field. The transition times vary inversely with

(56) Kober, E. M.; Meyer, T. J. Inorg. Chem. 1983, 22, 1614.

(57) DeSimone, R.; Drago, R. S. J. Am. Chem. Soc. 1970, 92, 2343

(58) Steiner, U. E. To be published. 
the magnetic field strength. Pertinent values for a magnetic field of $1 \mathrm{~T}$ are listed in Table III. The data show that at such a field the $\mathrm{T}_{0}^{\prime} \rightarrow \mathrm{T}^{\prime}{ }_{ \pm}, \mathrm{S}^{\prime}$ transitions are clearly faster than the estimated cage dissociation process of the radical pair ( $\sim 200 \mathrm{ps}$, vide supra). Thus, even if it is taken into account that $\mathrm{T}^{\prime}+$ and $\mathrm{T}^{\prime}$ - carry less than $25 \%$ of singlet character and that on the average only $1 / 3$ of the complexes will have their $z$ axes parallel to $\mathbf{B}_{0}$, one might expect that the magnetic field effect on $\eta_{\text {net }}$ is close to a saturation at $1 \mathrm{~T}$. Such a behavior is, however, not borne out by the experimental results according to which the effect is still linearly increasing at $1 \mathrm{~T}$. Preliminary measurements in our group extending to $3.3 \mathrm{~T}$ and the quantum yield data obtained with pulsed fields up to $5 \mathrm{~T}$ by Ferraudi and Arguello ${ }^{21}$ show that the slope of the magnetic field effect starts to decrease above $1.5 \mathrm{~T}$.

Two other features of the observed magnetic field dependence should be accounted for by an acceptable model of the mechanism. These are the minimum field on the order of $0.1 \mathrm{~T}$ required before the effect starts to rise and the weak viscosity dependence of the slope (cf. Table I).

A possible reason for the onset behavior may be related to the different kinetic natures of the competing processes: BET and dissociation are stochastic processes to which unique rate constants can be assigned. The rate of such processes is fastest at $t=0$. On the other hand, the magnetic-field-induced $\mathrm{T}_{0}^{\prime} \rightarrow \mathrm{T}^{\prime}{ }_{ \pm}, \mathrm{S}^{\prime}$ processes are of a coherent nature with their rate varying periodically in time, starting with rate zero at $t=0$. Since the net effect of the magnetic field on the efficiency of cage escape is obtained from a convolution of the time profiles of both types of processes, it is not unreasonable that the effect of the coherent process is borne out only if some minimum frequency is exceeded. It should be noted that a similar effect is apparent in the triplet mechanism., 9

Concerning the dependence of the magnetic field effect on solvent viscosity, it is remarkable that on increasing the viscosity by $200 \%$ the effect increases by $20 \%$ only. This observation may be discussed on the basis of eq 5 for the efficiency of net electron transfer

$$
\eta_{\text {net }}=\frac{k_{\text {dis }}}{k_{\text {dis }}+k_{\text {bef }} f\left(\mathbf{B}_{0}\right)}
$$

where the function $f\left(\mathbf{B}_{0}\right)$ accounts for the magnetic-field-dependent spin allowedness of BET. It will be a monotonically increasing function of $\mathbf{B}_{0}$ with a limiting value $\leq 1$. From eq 5 one can derive for the slope of the relative magnetic field effect $R$

$$
\mathrm{d} R \approx \frac{\mathrm{d} \eta_{\text {net }}}{\eta_{\text {net }}}=\frac{-\frac{\mathrm{d} f\left(\mathbf{B}_{0}\right)}{\mathrm{d} \mathbf{B}_{0}}}{k_{\text {dis }}+k_{\text {be }} f\left(\mathbf{B}_{0}\right)} \mathrm{d} \mathbf{B}_{0}
$$

Assuming that $k_{\text {bet }}$ and $f\left(\mathbf{B}_{0}\right)$ are not viscosity dependent, the viscosity dependence of $R$ is determined by $k_{\text {dis }}$ in the factor $\left(k_{\mathrm{dis}}\right.$ $\left.+k_{\text {bee }} f\left(\mathbf{B}_{0}\right)\right)^{-1}$. Since $k_{\mathrm{dis}}$ decreases with increasing solvent viscosity, an increase of $R$ is to be expected. From the fact that the viscosity dependence of $R$ is very weak as compared to that of $k_{\text {dis }}$ which should approximately vary as the inverse of the viscosity, one has to conclude that $k_{\text {bef }} f\left(\mathbf{B}_{0}\right)$ is larger than $k_{\text {dis }}$ even under conditions where $f\left(\mathbf{B}_{0}\right)$ has not attained its limiting high-field value. This conclusion is somewhat surprising and will have to be analyzed in more detail on the basis of quantitative dynamical treatment of our magnetokinetic model, which is currently being worked out.

\section{Conclusions}

Our investigations on the yield of net electron transfer $\left(\eta_{\text {net }}\right)$ in reductive and oxidative quenching of excited $\mathrm{Ru} \mathrm{u}^{\mathrm{Il}}$ trisbipyridyl complexes have provided clear evidence of triplet spin memory effects in the primary electron-transfer product ("radical pair").

In the reductive quenching of ${ }^{3^{\prime}}\left[\mathrm{Ru}(\mathrm{dce})_{3}\right]^{2+}$ by anilines this evidence is based on the pronounced effect of SOC increasing with the nuclear charge of a halogen substituent in the electron donor. Furthermore, it is supported by the magnetic-field-induced decrease of $\eta_{\text {net }}$ detectable in the case of strongest SOC with 4iodoaniline as a quencher. This effect is analogous to those observed in dye triplet quenching, ${ }^{9}$ where it has been attributed to triplet sublevel selective SOC (triplet mechanism). Since in the reductive quenching the transferred electron is localized on a dce ligand, SOC contributions of the reduced $\left[\mathrm{Ru}(\mathrm{dce})_{3}\right]^{+}$ complex are negligible.

In the oxidative quenching of ${ }^{3^{\prime}}\left[\mathrm{Ru}(\mathrm{bpy})_{3}\right]^{2+}$ by $\mathrm{MV}^{2+}$ evidence of triplet spin memory in the primary radical pair is based on the observation of a magnetic-field-induced decrease of $\eta_{\text {net }}$. This interpretation, which we have confirmed by various different experiments, is at variance with an assertion of Ferraudi and Argüello, ${ }^{21}$ who erroneously attributed their observation of a magnetic-field-induced decrease of the yield of free radicals to a reduction of the rate constant of quenching.

To explain the magnetic field effect on $\eta_{\text {net }}$, we have referred to the framework of a generalized radical-pair mechanism pertaining to RPs where the spin state of one of the radicals must be described as a strongly spin-orbit mixed Kramers doublet. Although such a situation may be formally treated with theoretical methods developed for the well-known radical-pair mechanism, it also exhibits features characteristic of the triplet mechanism. We expect that the specific situation encountered with the $[\mathrm{Ru}$ (bpy) $\left.]_{3}\right]^{3+} / \mathrm{MV}^{*+}$ radical pair is not unique in the field of redox photochemistry of transition-metal complexes and that further experimental and theoretical research on the dynamics of such reactions may benefit from the application of magnetokinetic methods.

Acknowledgment. This research was supported by the Deutsche Forschungsgemeinschaft. We are also indebted to the Fond der Chemischen Industrie for financial support. The project was initiated during a sojourn of $\mathrm{T}$. Ohno, who acknowledges the invitation as a guest professor by the University of Konstanz.

Registry No. $\mathrm{MV}^{2+}, 4685-14-7$; EDTA, 60-00-4; [Ru(bpy) $\left.{ }_{3}\right]^{2+}$, 15158-62-0; [Ru(dce $\left.)_{3}\right]^{2+}, 75324-93-5$; aniline, 62-53-3; 4-Cl-aniline, 106-47-8; 4-Br-aniline, 106-40-1; 2-I-aniline, 615-43-0; 4-I-aniline, 540$37-4$. 